\title{
"Sem gênero, idade, nação nem limites": por uma exposição histórica da moda como dispositivo de reinvenção identitária
}

"Genderless, ageless, nationless, limitless": for a historical exhibition of fashion as a device of identity reinvention

\section{Gender Bending Fashion}

Curadoria: Michelle Tolini Finamore Local e período: Museum of Fine Arts, Boston, Estados Unidos. De 21 de março a 25 de agosto de 2019. 


\section{TÁLISSON MELO DE SOUZA ${ }^{1}$}

ORCID: http://orcid.org/0000-0002-1456-0215

Depois de percorrer a exposição do acervo permanente do Museum of Fine Arts de Boston, e de visitar exposições relacionadas às trajetórias de duas mulheres artistas provenientes do país vizinho ao Sul, Frida Kahlo and Arte Popular ${ }^{2}$ e Graciela Iturbide's Mexico ${ }^{3}$, dirigi-me ao andar seguinte para o encontro com a próxima exposição. As únicas coisas que eu podia esperar: essa abordaria a questão de gênero, como informado por algum cartaz ou guia ao entrar na instituição, e teria de ser muito boa para me despertar da museum fatigue gerada por duas horas pelos outros três andares.

Uma passagem breve sob as esculturas de meninos pendidas do teto, de Jonathan Borofsky ${ }^{4}$, e pelas silhuetas pintadas na parede por Liliana Porter ${ }^{5}$, que evocavam metáforas de alteridade e sensação como se houvesse muito mais gente ali do que realmente havia. Então, deparei-me com uma longa linha do tempo horizontal disposta entre duas portas de vidro fechadas. Alguns anos entre meados do século XIX e o presente estavam destacados, conectados a textos com letras pequenas e algumas imagens "de época". Não me provocou curiosidade imediata, até que a primeira frase abordando as reações geradas pela emergência em público de mulheres trajando calças por volta de 1850 capturou minha atenção com referência a prisões vinculadas a uma publicação da ativista feminista Amelia Bloomer (1851), e às roupas da cirurgiã Dra. Mary Edwards Walker (1866): “I don't wear men's clothes, I wear my clothes!". E fui fisgado pelo potencial cultural e politicamente questionador da mostra; uma nova expectativa recobrou o ânimo para mais uma exposição naquele fim de sexta-feira, dia 22 de março.

Ainda que não tenha lido todos os verbetes e legendas (não imaginava que seria tomado pela vontade de escrever essa resenha ao fim da visita), captei referências a contextos no Ocidente, onde o uso de calças por mulheres ainda hoje é alvo de restrições, como em alguns tribunais nos EUA. Também o uso de ternos por elas, conectado à conquista ao voto e maior acesso ao mercado de trabalho (pautas urgentes de um segmento do feminismo naquele contexto, majoritariamente afeito às demandas de mulheres brancas de centros urbanos), ao redor dos anos de 1920. E a emergência do terno austero e sério do homem moderno, com seu

\footnotetext{
Doutorando no Programa de Pós-graduação em Sociologia e Antropologia da Universidade Federal do Rio de Janeiro. E-mail: talissonmelo@yahoo.com.br. E-mail: http://lattes.cnpq.br/6061720305924384.

2 Curada por Layla Bermeo, em cartaz de 27 de fevereiro e 29 de junho de 2019. No mesmo período, houve outra exposição dedicada à obra e trajetória de Kahlo, no Brooklyn Museum, Frida Kahlo: Appearances Can Be Deceiving, em cartaz de 8 de fevereiro a 12 de maio de 2019. Ambas enfatizam a relação da artista com seu vestuário, exibindo manequins com roupas que usara em diferentes ocasiões.

3 Curada por Kristen Gresh, em cartaz de 19 de janeiro a 12 de maio de 2019.

${ }^{4}$ I dreamed I could fly, 2000.

Untitled (Shadows), 1969-2014.
} 
own business e seus ideais, persistindo ainda hoje em ampla escala nos centros urbanos ocidentais (e ocidentalizados). Essa linha, no entanto, não se mantém sem muitos ruídos pululando desde intervenções dândi no vestuário do século retrasado até inversões ostensivas da cultura jovem urbana dos 1960, a exemplo de homens vestindo saias - ainda que se tratando do kilt tradicional escocês apropriado por Jacques Esterel, resguardando alguma conotação de masculinidade segura. No extremo, com data mais recente, foto do ator Billy Porter no red carpet do Oscar de 2019, usando vestido/smoking desenhado por Christian Siriano.

Nos últimos anos enfatizados no painel, uma envergadura nessas duas linhas pretensamente paralelas entre vestuário masculino e feminino era promovida por intercâmbios pontuais entre elementos conformadamente pertencentes à indumentária padrão de cada um dos dois gêneros possíveis, um arco ao longo de mais de um século e meio culminava em propostas "unissex", mais sistematicamente levadas às passarelas desde o início deste milênio, mesclando elementos associados aos padrões de cada gênero, ou irrompendo em configurações formais (estética e epistemologicamente) ambíguas, híbridas, andróginas, confusas e instigantes. Esse é um primeiro olhar, já que perturbam a normalidade das silhuetas padronizadas (e essencializadas) como "masculinas" e "femininas", porém, não se restringindo à promoção de uma leitura "do exótico", pois, nessa macrotemporalidade, tais manifestações pontuais de ruptura parecem reverberar no cotidiano, em constante tensão com vetores de força da incorporação e normalização dos papéis de gênero através dos códigos de vestuário.

Adentrei a primeira galeria, uma ambientação expográfica radicalmente distinta com relação às paredes e luzes brancas do hall onde observara a cronologia. Piso de madeira, paredes e divisórias em preto opaco, toda luz advinha de ninhos estruturados como prismas para envolver os manequins que davam corpo às peças, claramente apresentadas como obras de arte tecida pela curadora Michelle Tolini Finamore ${ }^{6}$.

No primeiro prisma, de luz laranja quente e vibrante, um manequim recebia visitantes de braços abertos e com vestido gender-fluid ${ }^{7}$ criado por Alessandro Trincone para a coleção primavera/verão 2017 Annodami, fundindo referências japonesas e italianas de design e alfaiataria, inspirada por vivência de opressão da infância do próprio estilista. Em grandes letras iridescentes, o título da mostra: Gender Bending Fashion. A tradução ao português é dificilmente literal, no entanto, imagens mecânicas de envergar, encurvar, empenar ou dobrar, rapidamente aguçaram minha imaginação brasileira (assombrado pelo anúncio de uma "nova era", na qual "meninos vestem azul e meninas vestem rosa", segundo a atual ministra brasileira da Mulher, Família e Direitos Humanos, Damares Alves (BORGES, 2019)),

\footnotetext{
${ }^{6}$ Website do museu para imagens da exposição: https://www.mfa.org/exhibitions/gender-bending-fashion.

7 Essa categoria é proposta pelo próprio estilista, entendo que se refere à utilização integrada de camisa, vestido, ao movimento e à forma da peça, bem como ao diálogo entre culturas de vestir distintas que estabelecem uma silhueta composta de curvas, ângulos e texturas que chamam atenção para a enorme gama de nuances entre os polos do vestuário padronizado em "silhueta masculina" e "silhueta feminina".
} 
e alcancei o sentido figurado de subjugação que apela aos vetores de poder entre moda e gênero, numa relação de mútua (trans)formação. Na parede ao lado da entrada, o paratexto curatorial posicionava e postulava as intenções e critérios do projeto: "How each of us categorizes our gender grows from a combination of societal expectations, learned habits, our personal experience of our own bodies, our senses of self and identity, and how we present ourselves to the world" (FINAMORE, 2019)8.

Uma playlist rodando ao fundo, não me apeguei a isso, nem tentei abstrair associações, mas como paisagem sonora ativava o corpo para o movimento, fluir e fruir à continuação de sucessivas obras do design de moda. A segunda sala, enorme e escura, concentrava todo resto da mostra, manequins isolados ou em grupos colocados em nichos triangulares de luzes em cores vibrantes, ou sobre pedestais altos, ou sobre uma estrutura de dois níveis que remetia tanto a vitrines quanto a passarelas - caso da maioria, em torno de 20 peças agrupadas ao fundo. Os destaques iniciais focavam produções icônicas da ruptura das regras generificadas da indumentária e da moda no século XX, como as jupe-culottes de Paul Poiret (1911), ou o conjunto com calças de Jeane Lanvin (1935-36), marcando as ousadias da alta-costura ao separar as pernas, ainda que sem romper radicalmente com as formas do vestido, um processo gradual que coloca as invenções de grife em diálogo com a moda das ruas de Paris e Nova York à época, ou mesmo das telas de cinema a partir dos anos 1930.

Predominantemente tecidas de conexões com a moda autoral das passarelas, as roupas como peças de museu de arte acentuavam formas, cores e texturas, e as colocavam em uma oscilante perspectiva temporal de inovações, apropriações e fusões mais ou menos ousadas - talvez, "legível" apenas por visitantes conhecedoras/es do universo da moda atual e historicamente, ou aqueles/as que, como eu, tentavam acompanhar as etiquetas e encontrar nelas a autoria e o ano de criação de cada peça -, como o terno preto "One Woman Show" de Viktor\&Rof para coleção outono/inverno 2003/2004, de cujo amplo decote saem outros decotes de blazers interiores; ou o terno florido com saia pregueada de Rei Kawakubo para Comme des Garçons 2012, com a silhueta híbrida de padrões masculino e feminino justapostos e deslocados.

Acho que híbrido não seria a melhor palavra, e a curadoria deixa isso evidente ao pendurar na parede central da sala uma pintura à óleo da coleção do museu, de autoria desconhecida, datada sem precisão como do século XIX, intitulada Two Children with Dog. As duas crianças bem pequenas, de rostos quase idênticos, vestem-se com o mesmo modelo de vestido, um com saia interior rosa, da que segura um chapéu azul, o outro com interior amarelo, da criança que traz um buquezinho de flores vermelhas, os sapatinhos também são iguais e os cortes de cabelo parecem reflexos. 0 deslocamento de mídia, retomando a pintura, que abunda nas exposições do acervo de arte europeia e norte-americana nas outras galerias, em meio a peças têxteis tridimensionais, parece instalar-se como um lembrete

\footnotetext{
3 Tradução do autor para: "Como cada um de nós categoriza nosso gênero vem de uma combinação de expectativas da sociedade, hábitos aprendidos, nossa experiência pessoal com nossos próprios corpos, nossos sentidos de self e identidade, e como nós apresentamos nós mesmos ao mundo".
} 
perspicaz sobre o aspecto cultural de configuração das regras de vestuário e seu papel na demarcação performativa do gênero de quem o veste.

Numa determinada idade, tanto de cada pessoa como de uma sociedade no curso de sua história, as regras ainda não se incorporam, não cobrem os corpos, ou cobrem-nos de maneiras outras, invertem seus códigos, fundem-nos, se apegam a determinadas cores, formas, texturas, restrições e otimizações de movimentos específicos e ratificações de valores. A moda reforça diferenças, muitas vezes polariza possibilidades de performances e expressões de sujeitos e grupos, e em muitos momentos a exposição nos leva a lembrar que, ali fora, essa influência é claramente identificável no emprego cotidiano dos vestires. Mas o que a seleção curatorial e sua expografia trazem à tona são as perturbações desses padrões. Enfatizam que a moda também pode, fornecendo a dimensão material que cobre e codifica os corpos, ao mesmo tempo constituir-se como dispositivo privilegiado na promoção de ruídos, impactando a linha reta da normalidade e fazendo dela sempre uma sinuosidade.

Ao evitar uma disposição estritamente cronológica dos modelos apresentados, a curadoria logra fazer saltar aos olhos uma movimentação constante, uma relação tensa na (in)adequação entre moda, sexo, identidade de gênero, sexualidade, e, indo além do que o título promete, tangenciam problemáticas de raça, classe, geração e culturas visuais e materiais regionais e nacionais ${ }^{9}$. Dali, alcancei o andar térreo, buscando, enfim, a saída do museu, mas se deu outra captura: Made Visible - Contemporary South African Fashion and Identity ${ }^{10}$, mas sua ressonância, indissociável da experiência de ver as delineações complexas que subjugam mutuamente moda e gênero, ficam como sugestão para a curiosidade de quem me lê.

\section{Referências}

BORGES, André. 'Fiz uma metáfora contra ideologia de gênero', diz Damares sobre vídeo. 0 Estado de São Paulo, 3 jan. 2019. Brasil. Disponível em: https://brasil.estadao.com.br/ noticias/geral,menino-veste-azul-e-menina-veste-rosa-diz-damares-alves,70002665826. Acesso em: 18 jul. 2019.

FINAMORE, Michelle Tolini. Gender Bending Fashion. Exposição. Boston: Museum of Fine Arts, 2019.

FINAMORE, Michelle Tolini. Gender Bending Fashion. Catálogo de exposição. Boston: Museum of Fine Arts, 2019.

\footnotetext{
9 Nas palavras do estilista e cineasta jordaniano-sírio-canadense Rad Hourani, reproduzidas no catálogo da exposição Gender Bending Fashion (FINAMORE, 2019, p. 2).

${ }^{10}$ Curada por Kathryn Gunsch, em cartaz de 2 de fevereiro a 12 de maio de 2019.
} 